\title{
Development of Metal-Resin Composite Restorative Material Part 2 Effects of acid and heat treatments of silver-tin filler particles on flexural properties of metal-resin composite
}

\author{
Somchai URAPEPON, Kiyoshi KAKUTA, Yukio MIYAGAWA, \\ Hideo OGURA, Chatcharee SUCHATLAMPONG ${ }^{2}$ and Apiwat RITTAPAI ${ }^{2}$ \\ Department of Dental Materials Science, \\ School of Dentistry at Niigata, The Nippon Dental University \\ 1-8 Hamaura-cho, Niigata City, Niigata, 951-8580, Japan \\ ${ }^{2}$ Faculty of Dentistry, Mahidol University \\ 6, Yothi Road, Rachathevi, Bangkok, 10400, Thailand
}

Received January 18, 1999/Accepted March 9, 1999

\begin{abstract}
The effects of acid and heat treatments of silver-tin filler particles on the flexural properties of metal-resin composite restorative materials were investigated. Five metal-resin composite restorative materials containing different silver-tin filler particles treated under different conditions were experimentally prepared. The conditions of the alloy particles were; 1) as atomized (NT), 2) $1.8 \% \mathrm{HCl}$ acid-treated $(\mathrm{AT}), 3)$ heat-treated at $150^{\circ} \mathrm{C}$ for $5 \mathrm{~min}$ after $\left.\mathrm{AT}(\mathrm{A} 15), 4\right)$ heattreated at $200^{\circ} \mathrm{C}$ for $5 \mathrm{~min}$ after AT (A20) and 5) heat-treated at $250^{\circ} \mathrm{C}$ for 5 min after AT (A25). The flexural strength and the flexural modulus of elasticity were measured for the five metalresin composites to evaluate the effects of the acid and heat treatments.

The flexural strength of the prepared composites was significantly influenced by the surface condition of the filler particles $(p<0.01)$, and increased significantly when the as atomized particles (NT) were acid-treated (AT) or acid- and heat-treated at $150^{\circ} \mathrm{C}$ (A15), but then significantly decreased as the heat treatment temperature increased (A20 and A25). The strength of the A15 composite was significantly higher than those of the other composites, and exceeded that (about $60 \mathrm{MPa}$ ) of the previous composite with no treatment. No significant difference was found in the flexural modulus of the composites.
\end{abstract}

Key words : Silver alloy, Dental composite, 4-META

\section{INTRODUCTION}

Metal-resin composite materials have been experimentally prepared by several researchers. Hirano et $a l^{11}{ }^{1)}$ used stainless steel particles as a filler to prepare a composite for magnetic cores of fixed prostheses. Kakuta et $a .^{2}{ }^{2)}$ used amalgam alloy particles as a filler to prepare a composite for a direct posterior restorative material, aiming to improve the wear resistance and durability of the present posterior composite. The maximum strength of these experimental metal-resin composites was reported to be $76^{1)}$ and $60^{2)} \mathrm{MPa}$, respectively which may need be further improved for posterior tooth application.

Kakuta et al. $^{2)}$ used 4-META as a coupling agent for their experimental composite. They reported that the strength of the composite was dependent on the bond between filler particles and resin matrix, and 4-META took an essential role in the 
bonding. It has been hypothesized that 4-META bonds with the alloy surface by hydrogen bonding between the carboxylic group or carboxylic anhydrous group of 4META and metal oxide on the alloy surface ${ }^{3)}$. Therefore, the bond strength and durability of the 4-META can be improved by oxidation of the alloy surface. This has been reported by several researcher ${ }^{4-10)}$ using various techniques. Echizenya ${ }^{4)}$ used Fourier transform infrared reflection absorption spectroscopy (FT-IR-RAS) and Xray photoelectron spectroscopy (XPS) to analyze the amount of resin adsorption by the alloy, and found that the adsorption was enhanced by increasing the hydroxyl groups on the alloy surface. Tanaka et al. ${ }^{5-10)}$ studied the effect of an alloy surface treatment on the adhesion of 4-META to the alloy. They found that conditioning of the alloy surface using either ion-coating ${ }^{5)}$, etching and immersion in an oxidizing agen $t^{6-8)}$ or heat treatment $t^{9,10}$ can improve the adhesive strength and adhesive resistance to water penetration of the 4-META and alloy interface. Therefore, it should be possible to increase the strength of the metal-resin composite by conditioning the filler particles in order to improve the bond strength between 4-META and alloy fillers.

The purpose of this study was to investigate the effects of acid and heat treatments of the silver-tin filler particles on the flexural properties of a metal-resin composite restorative material.

\section{MATERIALS AND METHODS}

The materials used in this study are listed in Table 1. Ag-Sn spherical alloy particles (73.2 mass\% Ag, 26.8 mass\%Sn) were produced by the research unit, Faculty of Dentistry, Mahidol University, Thailand, using an atomization method. Three particle sizes of the alloy, under $38 \mu \mathrm{m}, 38-45 \mu \mathrm{m}$ and $45-53 \mu \mathrm{m}$ were combined at the ratio of $3: 1: 1$ by mass, respectively and utilized for the filler of a metal-resin composite.

Table 1 Materials used in this study

\begin{tabular}{|c|c|c|c|}
\hline & Materials & Code & Batch No. \\
\hline Metal filler & Ag-Sn alloy particle ${ }^{1}$ & AS750 & 9608 AS750 \\
\hline Coupling agent & $\begin{array}{r}\text { 4-(2-Methacryloyloxyethoxycarbonyl) phthalic anhydride } \\
\text { (crystal form) }\end{array}$ & 4-META & $\mathrm{T} 1003$ \\
\hline Monomers & $\begin{array}{l}\text { 1,6-Bis (methacryloyloxy-2-ethoxycarbonyl-amino)- } \\
2,4,4(2,2,4) \text {-trimethylhexane } \\
\text { Triethylene glycol dimethacrylate }\end{array}$ & $\begin{array}{l}\text { UDMA } \\
\text { TEGDMA }\end{array}$ & 050155 \\
\hline Redox initiator & $\begin{array}{l}\text { Benzoyl peroxide } \\
\text { N, N-dimethyl-p-toluidine }\end{array}$ & $\begin{array}{l}\text { BPO } \\
\text { DMPT }\end{array}$ & $\begin{array}{l}40618 \\
\text { GA01 }\end{array}$ \\
\hline
\end{tabular}

\footnotetext{
${ }^{1}$ (Mahidol University, Bangkok, Thailand)

${ }^{2}$ (Sun Medical, Osaka, Japan)

${ }^{3}$ (Negami Kogyo, Negami, Japan)

${ }^{4}$ (Shin Nakamura Kagaku Kogyo, Osaka, Japan)

${ }^{5}$ (Sanken Kakou, Osaka, Japan)

${ }^{6}$ (Tokyo Kasei Kogyo, Tokyo, Japan)
} 
4-(2-methacryloyloxyethoxycarbonyl) phthalic anhydride (4-META) was used as the coupling agent. A base monomer, consisting of 1,6-Bis (methacryloyloxy-2-ethox ycarbonyl-amino)-2,4,4: (2,2,4)-trimethylhexane (UDMA, 75 mass\%) and tri-ethylene glycol dimethacrylate (TEGDMA, 25 mass\%), was used as the resin matrix. Either benzoyl peroxide (BPO, 1.0 mass \%) or N,N-dimethyl-p-toluidine (DMPT, 0.5 mass\%) was added to the base monomer as a redox initiator.

\section{Alloy particle surface treatment}

The alloy particles were immersed in $1.8 \% \mathrm{HCl}$ at $80^{\circ} \mathrm{C}$ and slowly stirred with a magnetic stirrer for $20 \mathrm{~min}$. After this acid treatment, the particles were thoroughly washed with distilled water until no residual acid remained on the surface. Washing was repeated until the removal of the acid was verified using $\mathrm{AgNO}_{3}$ which showed the existence of $\mathrm{HCl}$ due to the milky color of $\mathrm{AgCl}$. The particles were then filtered and dried at $50^{\circ} \mathrm{C}$ for $1 \mathrm{~h}$. After drying, the particles were divided into four groups. One of the four groups was used as acid-treated without heat treatment (AT) to prepare a metal resin composite, and the other three groups were placed in an oven for heat treatment at three different temperatures, $150^{\circ} \mathrm{C}$ for $5 \mathrm{~min}(\mathrm{~A} 15), 200^{\circ} \mathrm{C}$ for $5 \mathrm{~min}$ (A20), or $250^{\circ} \mathrm{C}$ for $5 \mathrm{~min}$ (A25). In addition to these four conditions, another condition of "as atomized without any treatment" (NT) was included, and thus five different surface conditions were investigated.

\section{4-META treatment and specimen preparation}

A 4-META acetone solution was prepared at a concentration of 2.5 mass \%, based on the results of the previous study ${ }^{2)}$. The five different particle groups (NT, AT, A15, A20 and A25 particles) were immersed in this solution at $80^{\circ} \mathrm{C}$ and slowly stirred using a magnetic stirrer for $2 \mathrm{~h}$. After this treatment, the particles were filtered and dried at $50^{\circ} \mathrm{C}$ for $1 \mathrm{~h}$. Treated alloy particles were then mixed with the prepared base monomers to produce two metal-resin pastes containing either BPO or DMPT. Each paste contained 93 mass $\%$ alloy particles, also based on the previous study ${ }^{2}$.

The specimens for the flexural test were prepared following ISO 4049 for Resinbased filling materials. Two metal-resin composite pastes were mixed at the ratio of 1:1 by mass for $1 \mathrm{~min}$. The mixture was filled in a $25 \times 2 \times 2 \mathrm{~mm}$ PTFE-coated stainless steel mold on top of a glass plate, using a syringe (C-R Syringe, Centrix Inc., CT, USA). Another glass plate was applied on top of the mold to remove any excess material. The assembly was held together by a C-clamp and immersed in $37 \pm 1{ }^{\circ} \mathrm{C}$ distilled water. Fifteen minutes after the start of mixing, the specimen was carefully removed from the mold and stored in distilled water at $37 \pm 1^{\circ} \mathrm{C}$ for $24 \mathrm{~h}$. The specimen was polished using \#1500 SiC paper, $3 \mu \mathrm{m}$ diamond paste (Metadi, Buehler Co.Ltd., IL, USA) and $0.05 \mu \mathrm{m}$ gamma alumina paste (Micropolish, Buehler Co.Ltd., IL, USA), and the dimensions measured before testing. Six specimens for each group were prepared. A three-point flexural test was carried out using a universal testing machine (Autograph DSS-5000, Shimadzu Co.Ltd., Kyoto, Japan) at a cross-head speed of $1 \mathrm{~mm} / \mathrm{min}$. The flexural strength $(\sigma)$ and the modulus of elasticity under 
flexural stress (flexural modulus, $E$ ) were calculated from formulae (1) and (2), respectively, as followed:

$$
\sigma=\frac{3 F l}{2 b h^{2}} \cdots \cdots(1)
$$

where $F$ is the maximum load $(\mathrm{N})$,

$l$ is the distance between the supports $(20 \mathrm{~mm})$,

$b$ is the width of the specimen $(\mathrm{mm})$,

$h$ is the height of the specimen $(\mathrm{mm})$.

$$
E=\frac{F_{1} l^{3}}{4 b h^{3} d} \cdots \cdots(2)
$$

where $F_{1}$ is the load at a convenient point in the straight-line portion of the trace $(\mathrm{N})$,

$l$ is the distance between the supports $(20 \mathrm{~mm})$,

$b$ is the width of the specimen $(\mathrm{mm})$,

$h$ is the height of the specimen $(\mathrm{mm})$.

$d$ is the deflection at load $F_{1}(\mathrm{~mm})$,

The data of flexural strength and elastic modulus were analyzed by one-way ANOVA, and the means were compared using Duncan's multiple range test.

$X$-ray photoelectron spectroscopy (XPS) and Scanning electron microscope (SEM) observation

The five different particles were washed with acetone. After washing, the particles were dried in a desiccator under vacuum at room temperature for $12 \mathrm{~h}$ and then placed on a carbon tape. The surface of the particles was analyzed using an X-ray photoelectron spectroscope (ESCA-750, Shimadzu Co.Ltd., Kyoto, Japan) with Al K $\alpha$ radiation under a pressure of $1.33 \times 10^{-5} \mathrm{~Pa}$. The binding energy of the measured photoelectron peak was calibrated by the C1s peak at a binding energy of $285.0 \mathrm{eV}$.

The fractured surfaces of the prepared composites after the flexural test were observed under a scanning electron microscope (JSM-T20, JOEL Co.Ltd, Tokyo, Japan) at $19 \mathrm{kV}$ of acceleration voltage at 350 and 2000 times magnification. In addition, the particle surfaces were observed at higher magnification $(\times 6000)$ using another scanning electron microscope (S-800, Hitachi Ltd, Tokyo, Japan) at $15 \mathrm{kV}$ of acceleration voltage.

\section{RESULTS}

The flexural strength of the experimental metal-resin composites ranged from 52.0 to 77.6 $\mathrm{MPa}$ and the flexural modulus from 12.2 to $14.5 \mathrm{GPa}$. Table 2 shows the results of the one-way ANOVA for the flexural strength and the flexural modulus. The flexural strength was significantly influenced by the different surface conditions of the alloy particles $(p<0.01)$. No significant difference among groups was found in the 
Table 2 Result of one way ANOVA for flexural strength and flexural modulus

\begin{tabular}{|c|c|c|c|c|c|}
\hline Source & df & Sum of Squares & Mean Squares & $\mathrm{F}$ value & $P$ value \\
\hline \multicolumn{6}{|l|}{ (Flexural strength) } \\
\hline Treatment & 4 & 2207.615 & 551.903 & 25.928 & $<0.001^{* *}$ \\
\hline Error & 25 & 532.151 & 21.286 & & \\
\hline Total & 29 & 2739.766 & & & \\
\hline \multicolumn{6}{|l|}{ (Flexural modulus) } \\
\hline Treatment & 4 & 24.278 & 6.069 & 1.689 & 0.184 \\
\hline Error & 25 & 89.835 & 3.593 & & \\
\hline Total & 29 & 114.113 & & & \\
\hline
\end{tabular}

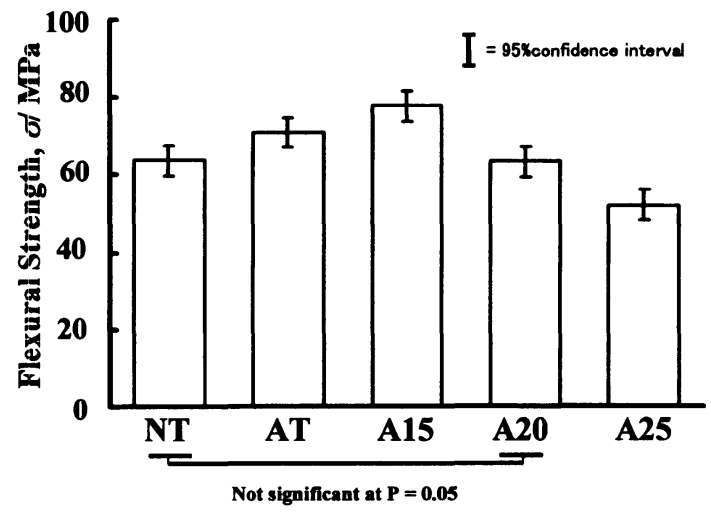

Fig. 1 The flexural strength of the experimental composite.

(comparison of the mean values by Duncan's multiple range test)

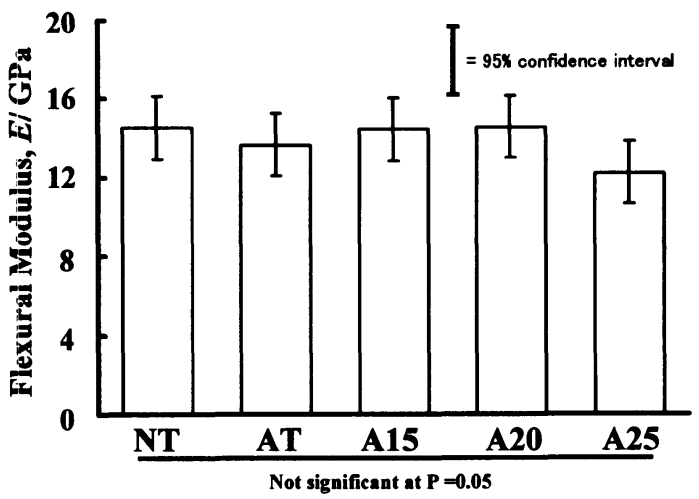

Fig. 2 The flexural modulus of the experimental composite.

(comparison of the mean values by Duncan's multiple range test) 
flexural modulus. Figs. 1 and 2 show the flexural strength and the flexural modulus of each experimental composite respectively.

As shown in Fig. 1, the flexural strength increased when the as atomized particles (NT) were acid-treated (AT) or acid-and heat-treated at $150^{\circ} \mathrm{C}$ (A15), but then decreased as the heat treatment temperature increased (A20 and A25). The mean flexural strength of A15 composite was the highest and significantly different from the others $(p<0.05)$. A25 composite was the lowest and also significantly different from the others $(p<0.05)$.

Scanning electron photomicrographs of the surfaces of the alloy particles from groups NT, AT, A15, and A25 are shown in Fig. 3. On the surfaces of all treated par-
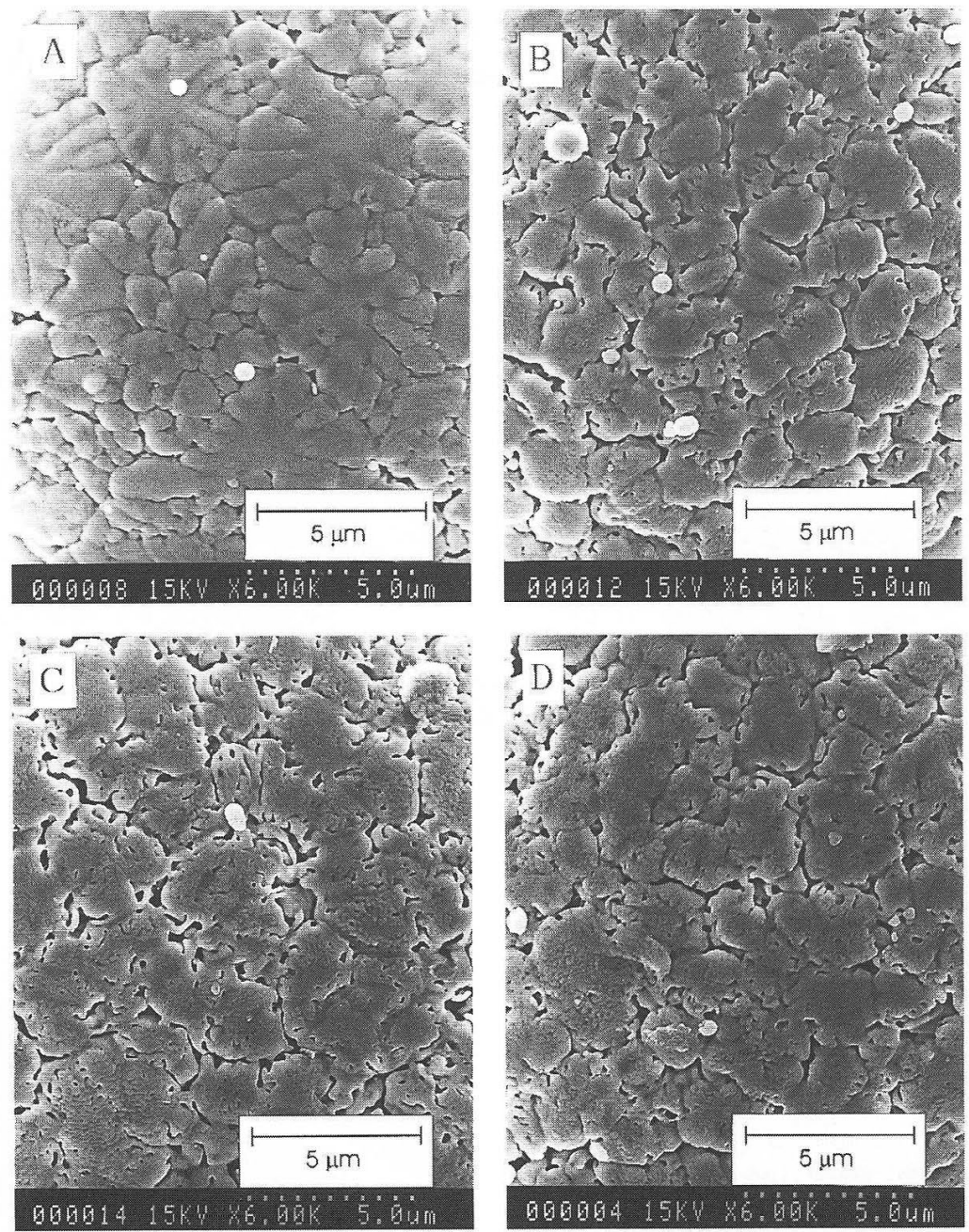

Fig. 3 SEM photograph of the NT particle surface (A), AT particle surface (B), A15 particle surface (C) and A25 particle surface (D) $(\times 6000)$. 
ticles, wider grooves at the grain boundaries than on NT particles were observed. No clear difference was found between the surfaces of the acid-treated particles and the acid- and heat-treated particles.

The fractured surfaces of A15 and A25 composites after the flexural test are shown in Figs. 4 and 5, respectively. A resin matrix was closely attached to the A15 particle surface, whereas it was separated from the surface of A25 in spite of the surface being similar to A15's.

The XPS spectra of Sn3d are shown in Fig. 6; the binding energy peak value of silver and tin, and element ratio on the metal surfaces are shown in Tables 3 and 4 respectively. Fig. 6 shows Sn 3d spectra obtained from AT and A25. In the dominant peak of Sn3d on AT, a shoulder was observed at the binding energy of $485 \mathrm{eV}$, which corresponds to the binding energy of tin in Table 3 . The shoulder became less clear as the heat treatment temperature increased and finally disappeared on A25.
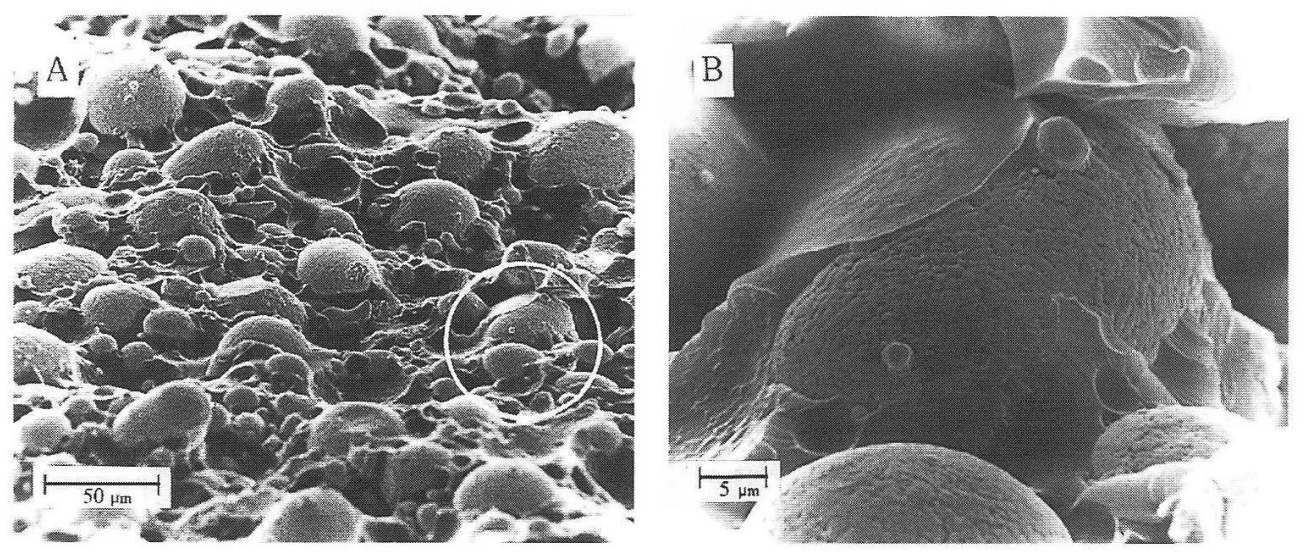

Fig. 4 SEM photograph of A15 fracture surface. Photograph B $(\times 2000)$ is an enlargement of the circle area in photograph $\mathrm{A}(\times 350)$.
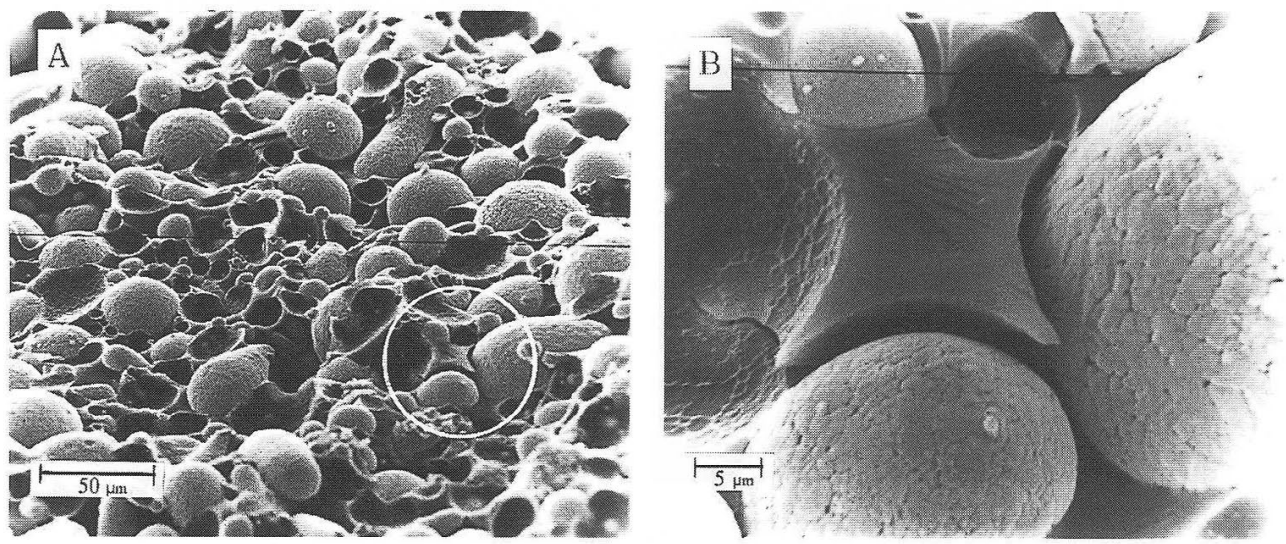

Fig. 5 SEM photograph of A25 fracture surface. Photograph $B(\times 2000)$ is an enlargement of the circle area in photograph A $(\times 350)$. 


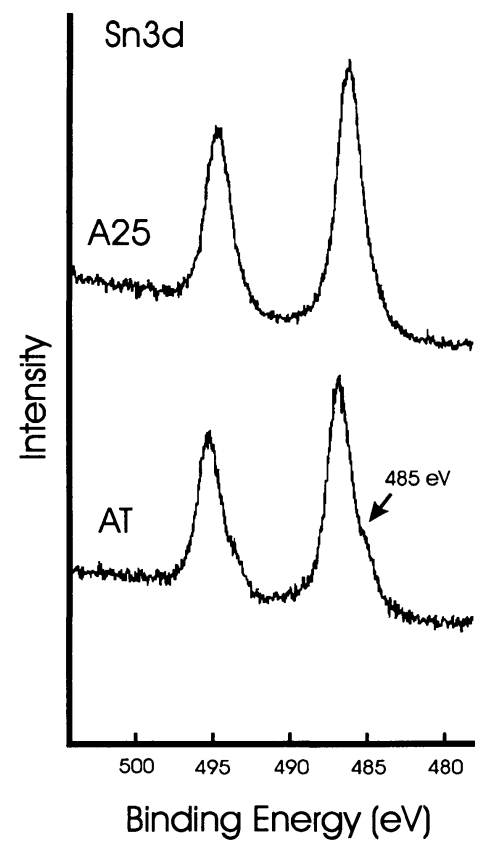

Table 3 Binding energy peaks $(\mathrm{eV})$ of $\mathrm{Ag}$ and $\mathrm{Sn}$ on the metal surface

\begin{tabular}{ccc}
\hline & $\mathrm{Ag} \mathrm{3d}$ & $\mathrm{Sn} \mathrm{3d}$ \\
\hline $\mathrm{NT}$ & 367.7 & 486.2 \\
\hdashline $\mathrm{AT}$ & 368.3 & 486.7 \\
\hline $\mathrm{A} 15$ & 368.1 & 486.4 \\
\hdashline $\mathrm{A} 20$ & 368.1 & 486.5 \\
\hdashline $\mathrm{A} 25$ & 368.3 & 486.3 \\
\hline $\mathrm{Ag}$ & $368.1-368.3^{1}$ & - \\
\hdashline $\mathrm{Ag}_{2} \mathrm{O}$ & $367.8^{2}$ & - \\
\hdashline $\mathrm{Sn}$ & - & $484.5-485.2^{1}$ \\
\hdashline $\mathrm{SnO}, \mathrm{SnO}_{2}$ & - & $486.0-489.0^{1}$ \\
\hline
\end{tabular}

${ }^{1}($ reference 21$)$

${ }^{2}$ (reference 22$)$

Fig. 6 Sn 3d spectra of AT and $\mathrm{A} 25$.

Table 4 Element ratio on the metal surface at $\mathrm{Sn} 3 \mathrm{~d}=100$ and $\mathrm{Ag} 3 \mathrm{~d}=100$

\begin{tabular}{c|c|c|c|c}
\hline & \multicolumn{2}{|c|}{ Sn $3 \mathrm{~d}=100$} & \multicolumn{2}{c}{$\mathrm{Ag} 3 \mathrm{~d}=100$} \\
\hline & $\mathrm{Ag} \mathrm{3d}$ & $\mathrm{O} 1 \mathrm{~s}$ & $\mathrm{Sn} 3 \mathrm{~d}$ & $\mathrm{O} 1 \mathrm{~s}$ \\
\hline $\mathrm{NT}$ & 29 & 215 & 345 & 741 \\
$\mathrm{AT}$ & 77 & 219 & 130 & 284 \\
$\mathrm{~A} 15$ & 70 & 241 & 143 & 344 \\
\hline $\mathrm{A} 20$ & 49 & 234 & 204 & 478 \\
\hline $\mathrm{A} 25$ & 18 & 200 & 556 & 1111 \\
\hline
\end{tabular}

Table 3 shows the binding energy peaks of $\mathrm{Ag}$ and $\mathrm{Sn}$ on the metal surface, indicating that the surfaces of all particle groups mainly consisted of $\mathrm{Ag}$ and $\mathrm{SnO}$ or $\mathrm{SnO}_{2}$ except NT which had $\mathrm{Ag}_{2} \mathrm{O}$ instead of $\mathrm{Ag}$. Due to the function level of the XPS, $\mathrm{SnO}$ and $\mathrm{SnO}_{2}$ could not be differentiated.

Table 4 shows the element ratio on the particle surface when either $\mathrm{Sn}$ or $\mathrm{Ag}$ is 100. When $\mathrm{Sn}$ was 100 , the ratio of silver was much higher on AT and A15 surfaces than on the other NT, A20 and A25 surfaces, and that of oxygen was not much different among the five surfaces. When $\mathrm{Ag}$ was 100 , the ratio of tin was lowest on the AT surface, and then increased with increasing heat treatment temperature, corresponding to the ratio of oxygen. 


\section{DISCUSSION}

In the previous study ${ }^{2)}$, a metal-resin composite was experimentally prepared using silver-tin amalgam particles as filler and 4-META as coupling agent, but its strength was not sufficient enough for posterior tooth restoration. In order to improve the strength, the effects of acid and heat treatments on the flexural properties were investigated in the present study. The alloy particles were self-produced with an exact ratio of silver and tin. This binary alloy system was chosen to simply analyze the effect of the treatments, since the silver-tin alloy particles used in the previous study ${ }^{2)}$ were an amalgam alloy containing small amount of copper.

The flexural strength of the experimental composite in this study significantly increased with acid treatment (AT) and heat treatment at $150^{\circ} \mathrm{C}$ (A15). The highest flexural strength obtained from A15 composite (77.6 MPa) was higher than NT by about $22 \%$. These results indicate that the bond between 4-META and the alloy particle surface could be improved by the aforementioned treatments of the alloy particles. As shown in Fig. 3, the grooves at the grain boundaries of AT, A15, and A25 were wider than those of NT. The wider grooves promote the adhesive property due to an increase of the bonding area and also higher mechanical interlocking between the alloy particle and resin matrix ${ }^{6)}$. However, the flexural strength decreased when the heat treatment temperature was higher than $200^{\circ} \mathrm{C}$. As shown in Figs.4 and 5, the fractured surface of A15 showed resin attached to the alloy surface, whereas the resin was found to be detached from the surface of A25. This indicates that the bond between the resin matrix and the A25 particles was not successful, which resulted in the lower strength of A25 composite. A question arises why this difference is induced in spite of the similar surfaces of A25 and A15. This could be explained by the increase of the elemental ratios for both tin and oxygen on the surface of A25 (Table 4), which would result a thicker oxide layer compared with A15. Previous studies ${ }^{8-11)}$ have shown that the amount and thickness of metal oxides on the surface largely influence the adhesive properties of 4-META to the alloy surface. Therefore, the result of the present study may be due to the negative or adverse effect of a thick oxide layer on the adhesive properties of 4-META to the alloy particle surface.

The higher strength of AT and A15 could be explained by the previous studies ${ }^{5,12-15)}$. Some of these studies ${ }^{5,12,13)}$ reported that an appropriate amount and thickness (very thin layer) of tin oxide played a positive role in adhesion between 4-META and tincoated or -containing alloys. On AT and A15 surfaces, lower ratios of Sn and O were found (Table 4) which might indicate that these surfaces had an appropriate oxide layer for good adhesion. In addition, the other studies ${ }^{14,15)}$ indicated that $\mathrm{SnO}$ had better adhesion than $\mathrm{SnO}_{2}$., It is probable that $\mathrm{SnO}$ is mainly formed on AT and A15 surfaces, although $\mathrm{SnO}$ and $\mathrm{SnO}_{2}$ could not be differentiated in this study. A further study may be required to differentiate the quality and quantity of $\mathrm{SnO}$ and $\mathrm{SnO}_{2}$ on metal surfaces, using standard specimens of $\mathrm{SnO}$ and $\mathrm{SnO}_{2}$ as described by Ohno et $a l .^{14)}$

Another point of view could be related to tin and silver. Mogi ${ }^{16)}$ reported that 
4-META strongly adhered to the polished surfaces of $\mathrm{Ag}$ and $\mathrm{Sn}$ in dry conditions. In the present study, tin was detected on both AT and A15 and silver was also found on these surfaces, which may be the cause of the improved adhesion.

As discussed above, there are many factors influencing the adhesion between 4-META and metal surfaces. Further studies are necessary to determine the individual effects of these factors.

The flexural moduli of the five groups were not significantly different from each other. This result suggests that the elastic modulus of metal-resin composites is independent of the bond between the resin matrix and the filler, as was found on the other composite materials ${ }^{17)}$.

During the experiment, we occasionally found the reactivity of the alloy particles, which could activate the polymerization of resin matrix and also 4-META itself. This reactivity has been further studied and reported by Miyagawa et $a{ }^{18,19)}$ The alloy reactivity could be enhanced by the type of metal element in the alloy ${ }^{18)}$, small amounts of water ${ }^{19)}$ and also high temperature ${ }^{20)}$. Since the 4-META treatment is carried out at $80^{\circ} \mathrm{C}$ for $2 \mathrm{~h}$, it is probable that the alloy reactivity promoted the polymerization of 4-META to some extent before the alloy was mixed with the resin matrix, and thus the bond between 4-META might not have bonded well with the resin matrix. In order to further improve the mechanical properties of the metal-resin composite, another coupling procedure which does not induce adverse effects of alloy particles should be developed.

\section{CONCLUSION}

The flexural strength of the prepared composites was significantly influenced by the surface condition of the filler particles $(p<0.01)$, and significantly increased when the atomized particles (NT) were acid-treated (AT) or acid- and heat-treated at $150^{\circ} \mathrm{C}$ (A15), but then significantly decreased as the heat treatment temperature increased (A20 and A25). The strength of the A15 composite was significantly higher than those of the other composites, and exceeded that (about $60 \mathrm{MPa}$ ) of the previous composite with no treatment. No significant difference were found in the flexural moduli of the composites.

\section{REFERENCES}

1) Hirano S., Yasukawa H., Nomoto R., Moriyama K. and Hirasawa T.: Properties of Magnetically Attractive Experimental Resin Composites, Dent Mater J, 15(2) : 91-97, 1996.

2) Kakuta K., Urapepon S., Miyagawa Y., Ogura H., Suchatlampong C. and Rittapai A.: Development of metal-resin composite restorative material; Experimental composite containing silver-tin alloy as filler. (will publish in Dent Mater J, 18(1), 1999)

3) Masuhara E.: A dental adhesive and its clinical applications, Quintessence Books Co., Tokyo, 1982, pp.11-68. (in Japanese)

4) Echizenya T.: Interfaces between metals and 4-META/MMA-TBBO, $J J$ Dent Mater, 11(4) : 628-641, 1992. (in Japanese)

5) Tanaka T., Hirano M., Kawahara M., Matsumura H. and Atsuta M.: A new ion-coating 
surface treatment of Alloys for dental adhesive resins, $J$ Dent Res 67(11) : 1376-1380, 1988.

6) Tanaka T., Fujiyama E., Shimizu S. and Atsuta M.: Study on surface treatment of nonprecious alloys for adhesion bridge, $J$ Jpn Prosthodont Soc, $27: 706-712,1983$. (in Japanese)

7) Tanaka T., Nagata K., Takeyama M., Atsuta M., Nakabayashi N. and Masuhara E.: 4-META opaque resin; A new resin strongly adhesive to nickel-chromium alloy, $J$ Dent Res, 60: 1697-1706, 1981.

8) Tanaka T., Fujiyama E., Shimizu S., Takaki A. and Atsuta M.: Surface treatment of nonprecious alloys for adhesion-fixed partial dentures, $J$ Prosthet Dent 55 : 456-462, 1986.

9) Tanaka T., Nagata K., Takeyama M., Atsuta M., Nakabayashi N. and Masuhara E.: Heat treatment of gold alloy to get adhesion with resin, $J J$ Soc Dent Appar Mater, $21: 95-102$, 1980. (in Japanese)

10) Tanaka T., Atsuta M., Nakabayashi N. and Masuhara E.: Surface treatment of gold alloys for adhesion, $J$ Prosthet Dent $60: 271-279,1988$.

11) Ohno H., Araki Y. and Sagara M.: The adhesion mechanism of dental adhesive resin to the alloy, Dent mater $J$ 5(1): 46-65, 1986.

12) Ohno H., Endo K., Araki Y.: A new method for promoting adhesion between metal alloys and dental adhesives, $J$ Dent Res 71(6) : 1326-1331, 1992.

13) Ohno H., Araki Y., Endo K.: ESCA study on dental alloy surfaces modified by Ga-Sn alloy, J Dent Res 71(6) : 1332-1337, 1992.

14) Ohno H., Yamane Y., Endo K., Araki Y., Iisuka Y.: Adhesion of adhesive resin to dental precious metal alloys (Part 1), Dent Mater $J$ 17(4):275-284, 1998.

15) Yamane Y., Ohno H., Konishi Y., Hirai T., Endo K., Araki Y.: Metal surface modification methods for adhesive heat curing resin, Transactions of Third international congress on dental materials, Abstract no P-160:290, November 1997.

16) Mogi T.: Studies on adhesion of methacrylic resin to cobalt-chromium alloy for denture base, J Jpn Prosthodont Soc $23: 660-667,1979$. (in Japanese)

17) Ferracane JL., Berge HX., Condon JR.: In vitro aging of dental composites in water; Effect of degree of conversion, filler volume, and filler/matrix coupling, $J$ Biomed Mater Res 42 : 465-472, 1998.

18) Miyagawa Y., Urapepon S., Ogura H. and Honda N.: Setting of UDMA containing BPO by metal powder and 4-META, $J J$ Dent Mater, 16 (Special issue 30): Abstract no P-28, 67, 1997. (in Japanese)

19) Miyagawa Y., Urapepon S., Ogura H. and Honda N.: New initiation system for resin polymerization with metal, Transactions of Third international congress on dental materials, Abstract no P-128 : 258, November 1997.

20) Odian G.: Principles of polymerization, $3^{\text {rd }}$ ed., John Wiley \& Sons Ltd., Singapore, 1991, pp.356-449.

21) Moulder J.F., Stickle W.F., Sobol P.E., and Bomben K.D.: Handbook of X-ray photoelectron spectroscopy, Perkin-Elmer Corp, MN, USA, 1992, pp.120-127.

22) Gaarenstroom S.W. and Winograd N.: Initial and final state effects in the ESCA spectra of cadmium and silver oxides, $J$ Chem Phys, 67(8) : 3500-3506, 1977. 